\title{
Ketamine Disrupts Theta Modulation of Gamma in a Computer Model of Hippocampus
}

\author{
Samuel A. Neymotin, ${ }^{1 \star}$ Maciej T. Lazarewicz, ${ }^{4 \star}$ Mohamed Sherif, ${ }^{2}$ Diego Contreras, ${ }^{5}$ Leif H. Finkel, ${ }^{4}$ \\ and William W. Lytton ${ }^{1,3,6}$ \\ ${ }^{1}$ State University of New York (SUNY) Downstate/New York University-Poly Joint Biomedical Engineering Program, Brooklyn, New York 11201, \\ Departments of ${ }^{2}$ Psychiatry and Behavioral Sciences, and ${ }^{3}$ Physiology and Pharmacology, and Neurology, SUNY Downstate Medical Center, Brooklyn, New \\ York 11203, ${ }^{4}$ Department of Bioengineering, University of Pennsylvania, Philadelphia, Pennsylvania 19104, ${ }^{5}$ Department of Neuroscience, University of \\ Pennsylvania School of Medicine, Philadelphia, Pennsylvania 19104, and ${ }^{6}$ Department Neurology, Kings County Hospital Center, Brooklyn, New York
} 11203

Abnormalities in oscillations have been suggested to play a role in schizophrenia. We studied theta-modulated gamma oscillations in a computer model of hippocampal CA3 in vivo with and without simulated application of ketamine, an NMDA receptor antagonist and psychotomimetic. Networks of 1200 multicompartment neurons [pyramidal, basket, and oriens-lacunosum moleculare (OLM) cells] generated theta and gamma oscillations from intrinsic network dynamics: basket cells primarily generated gamma and amplified theta, while OLM cells strongly contributed to theta. Extrinsic medial septal inputs paced theta and amplified both theta and gamma oscillations. Exploration of NMDA receptor reduction across all location combinations demonstrated that the experimentally observed ketamine effect occurred only with isolated reduction of NMDA receptors on OLMs. In the ketamine simulations, lower OLM activity reduced theta power and disinhibited pyramidal cells, resulting in increased basket cell activation and gamma power. Our simulations predict the following: (1) ketamine increases firing rates; (2) oscillations can be generated by intrinsic hippocampal circuits; (3) medial-septum inputs pace and augment oscillations; (4) pyramidal cells lead basket cells at the gamma peak but lag at trough; (5) basket cells amplify theta rhythms; (6) ketamine alters oscillations due to primary blockade at OLM NMDA receptors; (7) ketamine alters phase relationships of cell firing; (8) ketamine reduces network responsivity to the environment; (9) ketamine effect could be reversed by providing a continuous inward current to OLM cells. We suggest that this last prediction has implications for a possible novel treatment for cognitive deficits of schizophrenia by targeting OLM cells.

\section{Introduction}

Schizophrenia, a debilitating psychiatric disease affecting almost $1 \%$ of the population, remains a clinical conundrum due to the difficulty of connecting mind, thought, and behavior to underlying brain, network, neuron and synapse function and dysfunction. Recently, abnormalities in neural oscillations and synchronization have been noted in schizophrenia (Uhlhaas and Singer, 2006). This is significant because neural oscillations have been suggested as the underpinning of sensory binding (Gray and Singer, 1989). From this emerges the hypothesis that cognitive coordination, as a manifestation of oscillation-based neural co-

\footnotetext{
Received Jan. 28, 2011; revised June 6, 2011; accepted June 10, 2011

Author contributions:S.A.N., M.T.L., D.C., L.F., and W.W.L. designed research; S.A.N., M.T.L., M.S., D.C., L.F., and W.W.L. performed research; S.A.N., M.T.L., M.S., D.C., L.F., and W.W.L. analyzed data; S.A.N., M.T.L., M.S., D.C., and W.W.L. wrote the paper.

This work was supported by NIH Conte Center Grant MH-064045064045 (M.T.L.) and NIH Grant MH086638 (W.W.L.). We thank Michael Hines and Ted Carnevale (Yale University) for assistance with the NEURON simulator; Tom Morse (Yale) for ModeIDB support; Shaneel Shah (SUNY Downstate) for help with the model; Larry Eberle (SUNY Downstate) and Yosef Skolnick (Brooklyn College) for computer support; and the anonymous reviewers for their suggestions in improving this manuscript.

*S.A.N. and M.T.L. contributed equally to the work.

Correspondence should be addressed to Samuel A. Neymotin, SUnY Downstate, 450 Clarkson Avenue, Box 31, Brooklyn, NY 11203. E-mail: samn@neurosim.downstate.edu.

DOI:10.1523/JNEUROSCI.0501-11.2011

Copyright $\odot 2011$ the authors $\quad 0270-6474 / 11 / 3111733-11 \$ 15.00 / 0$
}

ordination, might be disrupted in schizophrenia and other psychotic disorders (Phillips and Silverstein, 2003; Olypher et al., 2006; Uhlhaas et al., 2006b). Recent investigations supported this, demonstrating visual perceptual organization abnormalities in schizophrenia associated with abnormal gamma oscillations (Uhlhaas and Silverstein, 2005; Uhlhaas et al., 2006a,b).

Hippocampus is centrally involved in the development of schizophrenia (Heckers, 2001; Tamminga et al., 2010). Schizophrenia patients have impaired hippocampal activity used in memory formation (Holthausen et al., 2003) and encoding of memory associations (Jessen et al., 2003; Achim et al., 2007). Structural studies revealed bilateral hippocampal reductions (Honea et al., 2005), as early as the first psychotic episode (Narr et al., 2004), and in drug-naive patients (Szeszko et al., 2003). Schizophrenia patients also have lower density of CA3 mossy fibers (Kolomeets et al., 2007), reduction in NMDARs in CA3 (Dean et al., 1999), and smaller pyramidal neurons (Benes et al., 1991; Zaidel et al., 1997).

Standard animal models of psychosis are induced by ketamine or phencyclidine, NMDAR antagonists which produce psychotic symptoms in normal individuals and worsen symptoms in schizophrenic patients. Previously, we demonstrated that ketamine produced a decrease in theta $(3-12 \mathrm{~Hz})$ and increase in gamma $(30-100 \mathrm{~Hz})$ power when given systemically in mouse 
(Ehrlichman et al., 2009; Lazarewicz et al., 2010). Human experiments replicated this: ketamine reduced low-frequency oscillation amplitude (delta, 1-5 Hz, theta-alpha, 5-12 Hz) and increased gamma amplitude (Hong et al., 2010). Increased gamma power appears paradoxical: NMDAR antagonism would be expected to reduce cell firing and reduce high-frequency activity. The hypothesis of Greene (2001) resolves this, suggesting that low concentrations of these psychotomimetics selectively block NMDARs on inhibitory circuits, while high concentrations produce anesthesia through antagonism of all NMDA-dependent transmission.

Here, we investigate possible mechanisms of ketamine's mode of action in vivo with a biophysically realistic computer simulation of hippocampus CA3. We first replicated baseline thetamodulated gamma oscillations of local field potentials (LFPs) observed experimentally. We then analyzed changes in these oscillations caused by removing NMDARs from combinations of the different cell types in the model. We found that selective blockage of NMDARs on oriens-lacunosum moleculare (OLM) cells reduced theta and amplified gamma power in agreement with experimental observations. We were able to recover the normal theta-gamma phasic relationship with tonic current injection into OLM cells. Given the dynamical similarities between hippocampus and neocortex, and the constant interactions between these structures, we expect that our results will generalize to provide better understanding of schizophrenia pathophysiology.

\section{Materials and Methods}

Simulations. Simulations were performed on a Linux system with 82.67 GHz Intel Xeon quad-core CPUs using NEURON (Hines and Carnevale, 1997). Eight seconds of simulation ran in $\sim 3 \mathrm{~min}$. To assess the robustness of the results, we ran each simulation condition with 5 different randomizations of synaptic inputs, and 5 different randomizations of network connectivity. Simulations were run in the NEURON simulation environment with python interpreter, multithreaded over 16-32 threads (Hines and Carnevale, 2001; Carnevale and Hines, 2006; Hines et al., 2009). Analysis of simulation data was done with the Neural Query System (Lytton, 2006) and Matlab (MathWorks). The full model is available on ModelDB (https://senselab.med.yale.edu/modeldb/showmodel. asp? model $=139421$ ).

Cells and connections. The network consisted of 800 five-compartment pyramidal cells, 200 one-compartment basket interneurons, and 200 one-compartment OLM interneurons (Wang and Buzsaki, 1996; Wang, 2002; Tort et al., 2007). Current injections (pyramidal cells: 50 pA; OLM cells: $-25 \mathrm{pA}$ ) were added to get baseline activity. This was a simplification to substitute for absence of external inputs from other areas, and to compensate for the small size of the model, which did not allow for much self-activation. Periodic inhibition from medial septum (MS) paced interneurons in all simulations except for those shown in Figure 5 (see below) to model the function of medial septum as a pacemaker (Stewart and Fox, 1990; Hangya et al., 2009). All cells contained leak current, transient sodium current $I_{\mathrm{Na}}$, and delayed rectifier current $I_{\mathbf{k}-\mathbf{d r}}$, to allow for action potential generation. Additionally, pyramidal cells contained in all compartments potassium type A current $I_{\mathrm{K}-\mathrm{A}}$ for rapid inactivation, and hyperpolarization-activated current $I_{\mathrm{h}}$ to allow for bursting. The OLM cells had a simple calcium-activated potassium current $I_{\mathrm{KCa}}$ to allow long lasting inactivation after bursting, high-threshold calcium current $I_{\mathrm{L}}$ to augment bursting and to activate $I_{\mathrm{KCa}}$, hyperpolarizationactivated current $I_{\mathrm{h}}$ for bursting, and intracellular calcium concentration dynamics. Selection of currents was based on prior published models (Tort et al., 2007; Stacey et al., 2009).

Network schematic is shown in Figure 1. There were 152,000 synapses. Pyramidal cell projections were mixed AMPA and NMDA response. Basket cells synapsed on the soma of both pyramidal cells and other basket cells via $\mathrm{GABA}_{\mathrm{A}}$ receptors. OLM cells connected to distal dendrites of pyramidal cells via $\mathrm{GABA}_{\mathrm{A}}$ receptors. AMPA and NMDA receptors had

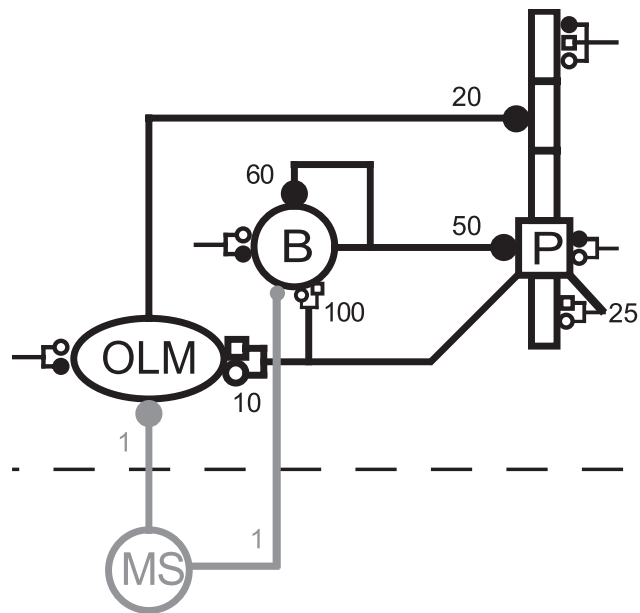

Figure 1. Schematic representation of the network. Each symbol represents a population: $P$, 800 pyramidal cells; B, 200 basket cells; 0LM, 200 OLM cells. Convergence values (number of inputs for an individual synapse) are shown near synapses: $G_{A B A}$ receptors (filled circles), AMPA receptors (open circles), NMDA receptors (open squares). External stimulation from other areas was modeled by synaptic bombardment (synapses with truncated lines). Externally generated theta oscillations from the MS were imposed on OLM and basket cells.

\section{Table 1. Synaptic parameters}

\begin{tabular}{lllccl}
\hline Presynaptic & Postsynaptic & Receptor & $\tau_{1}(\mathrm{~ms})$ & $\tau_{2}(\mathrm{~ms})$ & Conductance (nS) \\
\hline Pyramidal & Pyramidal & AMPA & 0.05 & 5.3 & 0.02 \\
Pyramidal & Pyramidal & NMDA & 15 & 150 & 0.004 \\
Pyramidal & Basket & AMPA & 0.05 & 5.3 & 0.36 \\
Pyramidal & Basket & NMDA & 15 & 150 & 1.38 \\
Pyramidal & OLM & AMPA & 0.05 & 5.3 & 0.36 \\
Pyramidal & OLM & NMDA & 15 & 150 & 0.7 \\
Basket & Pyramidal & GABA $_{A}$ & 0.07 & 9.1 & 0.72 \\
Basket & Basket & $\mathrm{GABA}_{\mathrm{A}}$ & 0.07 & 9.1 & 4.5 \\
OLM & Pyramidal & $\mathrm{GABA}_{\mathrm{A}}$ & 0.2 & 20 & 72 \\
MS & Basket & $\mathrm{GABA}_{\mathrm{A}}$ & 20 & 40 & 1.6 \\
MS & OLM & $\mathrm{GABA}_{\mathrm{A}}$ & 20 & 40 & 1.6 \\
\hline
\end{tabular}

reversal potentials of $0 \mathrm{mV}$, while $\mathrm{GABA}_{\mathrm{A}}$ receptors had reversal potentials of $-80 \mathrm{mV}$.

Connections in the network were set up based on fixed convergences (Fig. 1). However, connectivity was random and specific divergence could therefore vary. All synaptic delays between cells were $2 \mathrm{~ms}$, to simulate axonal propagation and neurotransmitter diffusion and binding, which were not explicitly modeled. Parameters were based on the literature where available, as well as on previous models (White et al., 2000; Tort et al., 2007). Parameters were tuned to reproduce theta (3-12 $\mathrm{Hz}$ ), gamma $(30-100 \mathrm{~Hz})$, and theta-modulated gamma oscillations with sparse firing of pyramidal cells. The medial septum input to interneurons was simulated as $150 \mathrm{~ms}$-interval synaptic conductances with rise time of $20 \mathrm{~ms}$, offset time of $40 \mathrm{~ms}$, and reversal potential of $-80 \mathrm{mV}$.

Synapses. Synapses were modeled by a standard NEURON doubleexponential mechanism with parameters based on Tort et al., 2007 (Table 1). Magnesium block in NMDA receptors used the experimental scaling factor $1 /\left(1+0.28 \cdot \mathrm{Mg} \cdot e^{-0.062 \cdot \mathrm{V}}\right) ; \mathrm{Mg}=1 \mathrm{mM}(\mathrm{Jahr}$ and Stevens, 1990). At $-75 \mathrm{mV}$, AMPA response peak amplitude was $1.15 \mathrm{mV}$ and NMDA response peak amplitude was $0.1 \mathrm{mV}$, whereas for $-61 \mathrm{mV}$ they were $1.75 \mathrm{mV}$ and $0.65 \mathrm{mV}$, respectively.

Background activity. Throughout the simulation duration, background activity was simulated by synaptic excitatory and inhibitory inputs following a Poisson process, sent to somata of all cells and dendrites of pyramidal cells (Table 2). Fast background activity consisted of AMPA and GABAergic bombardment at $1000 \mathrm{~Hz}$. Slow activity used activation of the NMDA receptors at a mean frequency of $10 \mathrm{~Hz}$. These inputs represented the influence of surrounding excitatory and inhibitory cells 
Table 2. Parameters for modeling background activity

\begin{tabular}{lllccl}
\hline Cell & Section & Synapse & $\tau_{1}(\mathrm{~ms})$ & $\tau_{2}(\mathrm{~ms})$ & Conductance (nS) \\
\hline Pyramidal & Soma & AMPA & 0.05 & 5.3 & 0.05 \\
Pyramidal & Soma & GABA $_{\mathrm{A}}$ & 0.07 & 9.1 & 0.012 \\
Pyramidal & Dendrite & AMPA & 0.05 & 5.3 & 0.05 \\
Pyramidal & Dendrite & NMDA & 15 & 150 & 6.5 \\
Pyramidal & Dendrite & GABA A $_{A}$ & 0.07 & 9.1 & 0.012 \\
Basket & Soma & AMPA & 0.05 & 5.3 & 0.02 \\
Basket & Soma & GABA $_{\mathrm{A}}$ & 0.07 & 9.1 & 0.2 \\
OLM & Soma & AMPA & 0.05 & 5.3 & 0.0625 \\
OLM & Soma & GABA $_{\mathrm{A}}$ & 0.07 & 9.1 & 0.2 \\
\hline
\end{tabular}

of spikes of the given population in each $1 \mathrm{~ms}$ interval. Then the mean was removed and the spectral power was calculated using the multitaper method (MatLab pmtm() function; MathWorks). Peak values in the power spectra are reported.

To calculate ketamine effects, we compared against baseline in each power band (theta, 3-12 Hz; gamma, 30-100 Hz): (mean ketamine $_{-}$ mean $_{\text {control }} / \mathrm{SD}_{\text {control }}$, using mean and $\mathrm{SD}$ of power, and reported in units of SDs from the mean (see Fig. 6, SD units).

To measure information transfer through the network, we used our previously described methods (Neymotin et al., 2011a). Briefly, normalized transfer entropy (nTE) (Gourévitch and Eggermont, 2007) was measured from binned background (external) AMPA inputs to spike outputs for all excitatory neurons, using $15 \mathrm{~ms}$ bins. To

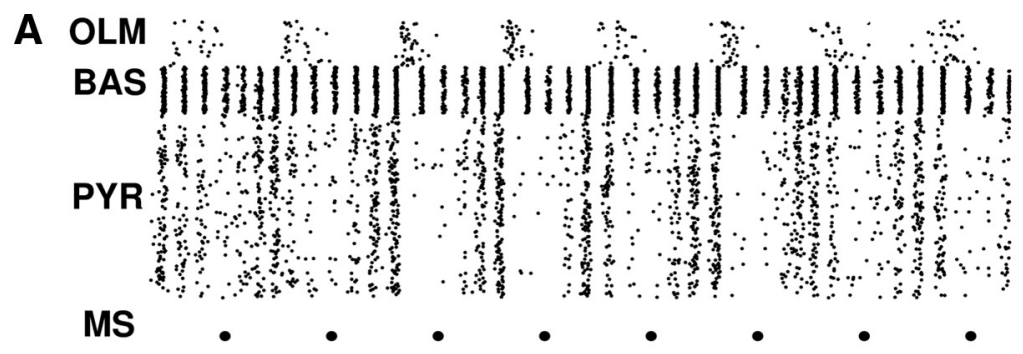
obtain enough data to get consistent results from the nTE analysis, these simulations were run for 30 s of model time.

Approximately 1000 simulations were performed in the course of initial parameter tuning, to obtain activity with the appearance of the experimental controls. Subsequent explorations of the model were performed with $>500$ simulations. Final evaluations to produce the results presented here were made over the course of $\sim 1000$ additional simulations. A typical single simulation ( $8 \mathrm{~s} ; 1200$ neurons) took $\sim 3$ min using 16 threads on a $2.67 \mathrm{GHz}$ Intel Xeon quad core CPU. Simulations were tested with pharmacological blockades or subnetwork isolations to evaluate particular circumstances and to determine the origins of activity patterns.

C
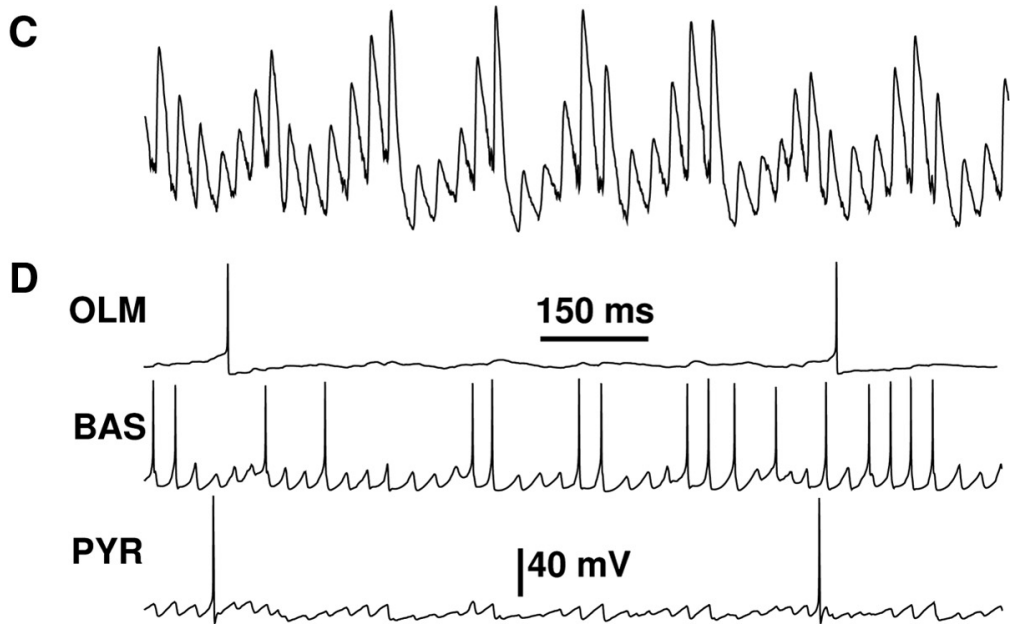

Figure 2. Activity during baseline simulation. $A$, Raster plot (all 1200 cells are shown but many spikes obscured due to vertical overlap). B, Spike densities (1 ms bins; 3 ms triangle filter smoothing). C, LFP. D, Selected single cell voltage traces. BAS, Basket cell; PYR, pyramidal cell.

not explicitly modeled in the simulation and produced a high conductance state similar to that observed in vivo (Destexhe et al., 2003). In addition, we placed slow excitatory inputs in the last distal apical compartment of pyramidal cells, to model input from the entorhinal cortex. This input was capable of simulating calcium-spike-like activity in the dendritic compartment and driving sparse firing of pyramidal cells.

Synapses were activated randomly according to a Poisson distribution. LFP was simulated by a sum of differences in membrane potential between the most distal apical and the basal dendritic compartment over all pyramidal cells. Before calculating spectral power, the DC component of the signal was removed (Oppenheim et al., 1999). Power in a frequency band was calculated by summing spectral power in the appropriate frequency ranges. To assess population frequencies for the different classes of cells, multiunit activity vectors were formed by counting the number

\section{Results}

Simulation reproduces thetamodulated gamma oscillations

An in vivo pattern of theta-modulated gamma oscillation was generated by interactions among the three subpopulations represented in the network (Fig. 2). Pyramidal cells drove OLM and basket cells via AMPA and NMDA receptor activation. The OLM cells periodically inhibited the distal dendrites of pyramidal cells, while the basket cells inhibited the soma of pyramidal cells. Compared with the fast changes in the membrane potential of pyramidal somas caused by basket cells, dendritic filtering gave the OLM inputs longer time constants, allowing them to modulate pyramidal activity with a slower time course. Inhibitory connections among basket cells, and between basket cells and pyramidal cells, produced gamma rhythms. This is seen in the synchronous, highfrequency spiking activity of the basket cell and pyramidal cell populations in the raster (Fig. 2A) and spike-densities (Fig. 2B), and reflected in similar high-frequency activity in the LFP (Fig. 2C).

Theta drive from medial septum (MS) was simulated by providing periodic inhibitory input to OLM and basket cells every $150 \mathrm{~ms}$ (Fig. 2A, dots at bottom). The primary direct effect of the periodic MS inputs was to turn off OLM activity (Fig. $2 A, B$ ). Although the MS inhibitory projections onto basket cells and OLMs were equal, OLM depression was far more pronounced due to the greater overall drive received by basket cells through balanced inhibitory and excitatory interactions from other basket cells and from pyramidal cells. OLM inhibition resulted in peri- 
odic disinhibition of pyramidal cells (Fig. $2 A, B$; note increased firing of pyramidal cells after MS inputs). However, due to the time constants associated with both delays and cell response times, this pyramidal cell response occurred in antiphase with the MS drive.

During the period of disinhibition, pyramidal cell activity gradually ramped up to the antiphase peak, a matching of intrinsic and extrinsic time constants that suggested that the hippocampal network may be tuned to theta frequency (tested below). The antiphase peak can be seen in the pyramidal cell spike density (Fig. $2 B$ ) and is reflected in the LFP amplitude (Fig. $2 C)$. From this peak, pyramidal cells drove both OLMs and basket cells. The basket cell drive contributed to the amplitude of ongoing gamma oscillation. Activation of OLM produced reduced pyramidal cell activity, a drop in spike density, reduced LFP, and reduced gamma amplitude, until interruption by the next MS input completed the cycle. All three populations skipped cycles, demonstrating that the dominant frequencies emerged as a population effect (Fig. 2).

Via this sequence of interactions, the entire network reflected the imposed theta from the periodic medial septal activation, resulting in theta-modulated gamma activity. Though the theta activity was imposed, the gamma activity emerged from basket-pyramidal interactions, producing an appearance similar to that seen in vivo (Bragin et al., 1995, their Fig. 1a). We noted several similarities with these experimental results beyond the basic theta-gamma co-modulation. First, the upslope of the theta demonstrated an increasing gamma amplitude similar to the ramp-up augmentation which we saw with the model. This ramp-up augmentation can be explained by the model: it resulted from the gradual release from OLM inhibition by the pyramidal cell population. Second, the theta was asymmetrical in both the experimental and simulated traces: the slow ramp-up contrasts with a relatively abrupt drop in theta. The model demonstrated that the drop-off was a consequence of the rapid turning off of activity due to the compact OLM burst. Third, we noted that gamma activity was persistent throughout the cycle. This is explained in the simulation by noting that two mechanisms of gamma generation coexist, so that the basket cell-only mediated form (Interneuron Network Gamma, ING) can carry on during the theta nadir despite relatively little pyramidal activity.

\section{Contributions of PING/ING to gamma oscillations}

Using analysis of simplified models, gamma generation can be grossly dichotomized as being due to ING or PING (Pyramidal Interneuron Network Gamma) (Lytton and Sejnowski, 1991; Whittington et al., 2000). In a reduced model analysis these mechanisms are considered alternatives (Wang and Buzsaki, 1996; Börgers and Kopell, 2003), but the complexity of the current simulation allows both of them to be expressed to some extent during different activity phases. As described above, ING appeared to be the major gamma driver at the theta nadir (Fig. 2C), when pyramidal cell population activa-
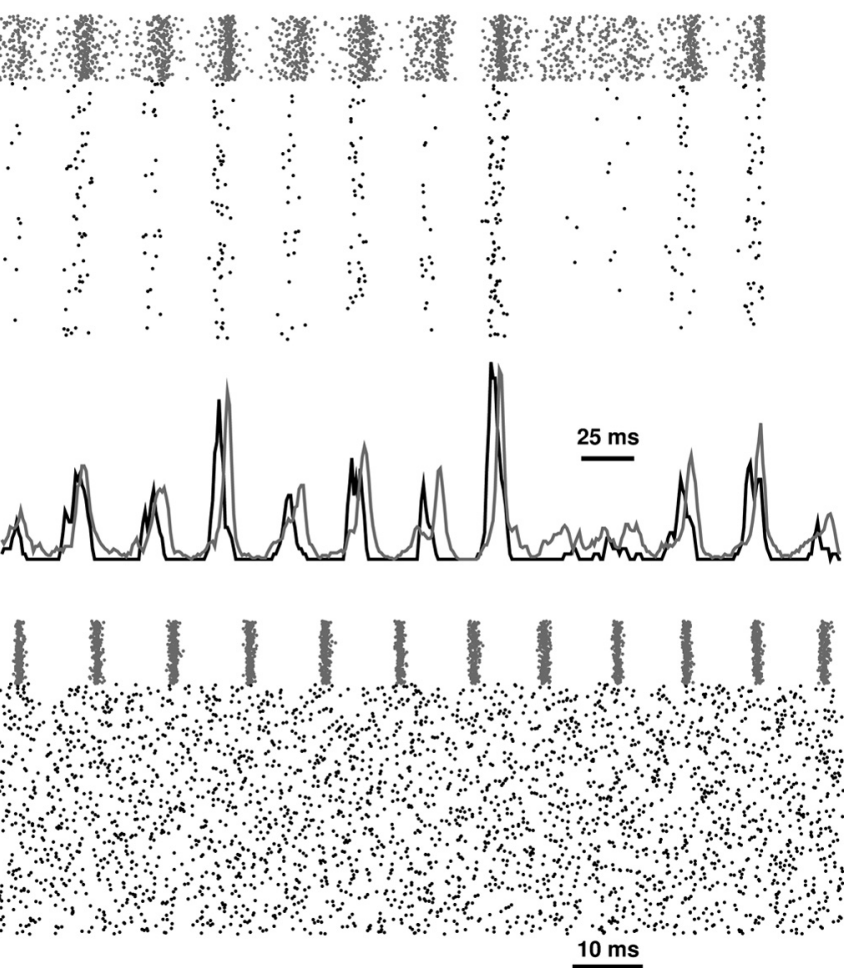

$0 \mathrm{~ms}$

Figure 3. Isolation of PING and ING mechanisms. A, PING. Raster (top) and spike densities (bottom). Gamma ( $30 \mathrm{~Hz}$ ) is produced by interaction between the two populations. $\boldsymbol{B}$, ING; Raster. Ongoing pyramidal activity drives the inhibitory network which then produces gamma $(93 \mathrm{~Hz})$ internally. Note difference in scale bars.

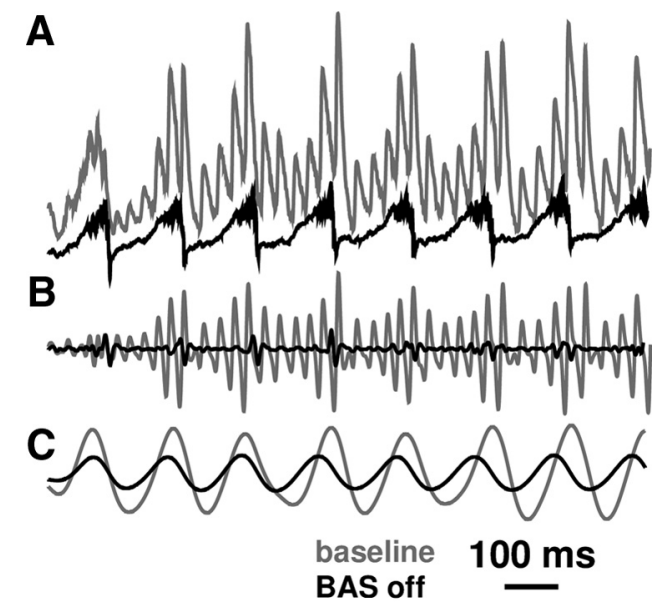

Figure 4. Reduction of theta in absence of basket cell activity. $\boldsymbol{A}$, Unfiltered LFP. $\boldsymbol{B}$, LFP gamma band $(30-100 \mathrm{~Hz})$. C, LFP theta band $(3-12 \mathrm{~Hz})$.

tion was minimal (Fig. $2 \mathrm{~A}$ ). By contrast, during the theta upswing, gamma activity appeared to primarily emerge as a PING interplay, the pyramidal cells drove the basket cells which then coordinated population pyramidal-cell activity through near-simultaneous basket cell IPSPs on pyramidal cell somata (Wang and Buzsaki, 1996). However, as the basket cell population attempted to follow the pyramidal cell drive, its response was shortened by basket-to-basket effects (ING), an effect that then fed back around the loop to shorten the pyramidal cell gamma cycle. OLM cells contributed at the beginning of the cycle, attenuating the pyramidal response which then reduced basket cell firing. This then also reduced the sharpness of the basket cell response. 
Single cell voltage traces reflected the dominant frequencies of basket cells and pyramidal cells (Fig. 2D). Individual OLM cells showed periodic firing on portions of the theta cycles after the recovery from MS inputs. The basket cell population fired at gamma frequency, but individual cells would only follow for 3-4 cycles at a time, and only at peak theta. The underlying gamma rhythm was observable in the subthreshold drive of both basket cells and pyramidal cells. Basket cells tended to fire at the gamma peak in the LFP, while pyramidal cells tended to fire at the gamma nadir (Fig. 2D; note antiphase relation of pyramidal cell and basket cell spikes).

We looked at dynamical subsets of the system to isolate the complementary ING/PING effects (Fig. 3).

To isolate reciprocal pyramidal-basket interactions, we reduced basket-basket connections to $10 \%$ of baseline, removed OLM to pyramidal connections, and turned off medial septal inputs to disable theta drive. In this partially isolated system, the pyramidal cell population fired together, driving the smaller basket cell population to fire at high rates. This produced prolonged inhibition which then delayed the firing of pyramidal cells in the next gamma cycle in a PING-like interaction (Fig. 3A, bottom traces) (Lytton and Sejnowski, 1991; Börgers and Kopell, 2003; Tiesinga and Sejnowski, 2009). In this system, with only $10 \%$ basket-to-basket GABAergic coupling, basket cell population frequency was lowered from $\sim 35$ to $30 \mathrm{~Hz}$ due to reduction in the inhibition of these inhibitors. In this way, basket-basket connections can be viewed as both speeding up and sharpening the largely PING oscillation by shortening the time window for excitation of basket cells after an excitatory impulse from pyramidal cells.

A relatively isolated ING mechanism was produced by looking at the connected basket cell population driven by the pyramidal cells (Fig. $3 A$ ). In this simulation, pyramidal cells were disinhibited, removing feedback from basket cells as well as inputs from other populations. The driven basket cell network now produced faster synchronous oscillations with a cycle of $\sim 10.7 \mathrm{~ms}(93 \mathrm{~Hz})$, similar to frequencies observed in vitro (Cobb et al., 1997). This pronounced difference in frequencies (3-fold higher for ING compared with PING) served as a signature, allowing us to determine the relative contribution of ING and PING after manipulations of the full network.

\section{Basket cells augment theta}

Basket cells were entrained to theta at two levels: directly by the MS inputs and indirectly via the periodic firing of the OLMdisinhibited pyramidal cells. The basket cells then provided feedback onto pyramidal cells that augmented their theta response. Strong consequent inhibition of pyramidal somata by both basket cells and OLMs on the theta trough produced large periodic somatic hyperpolarization which was reflected strongly in the LFP. Removal of the basket cell population greatly reduced theta strength (Fig. 4), demonstrating that basket cells contribute strongly to theta (Fig. 4C), as well as to gamma (Fig. 4B). Inhibition of the pyramidal soma by basket cells was strongest on the trough of the theta cycle, which made hyperpolarization of the pyramidal cell soma larger with this periodicity. Because OLMs synapse on dendrites while basket cells synapse on somata, basket cells produced a longer dipole that had more effect on the LFP as well as having a more immediate effect on spike generation. In the absence of basket cell firing, this LFP amplification between somata and distal dendrites of pyramidal cells was absent.

Basket cells have been implicated as important pacemakers in the generation of fast rhythms from beta up to ripple. Here we
A

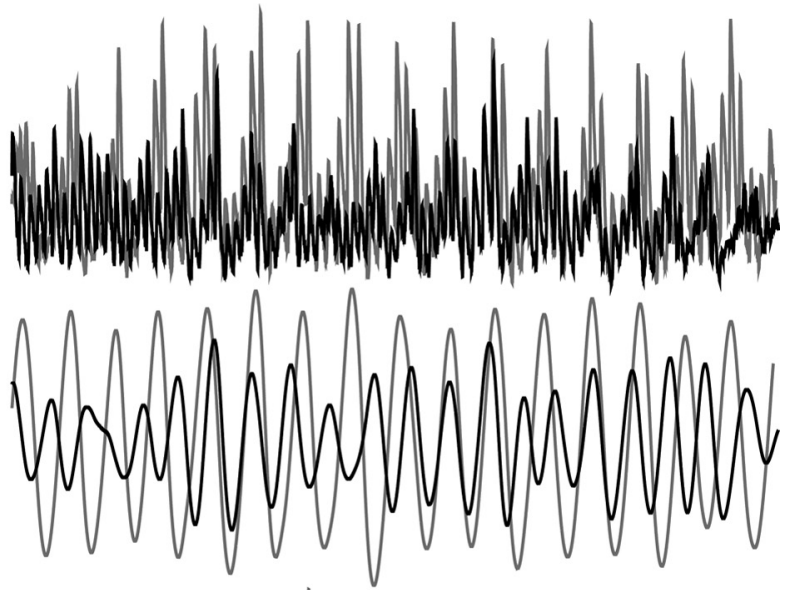

C
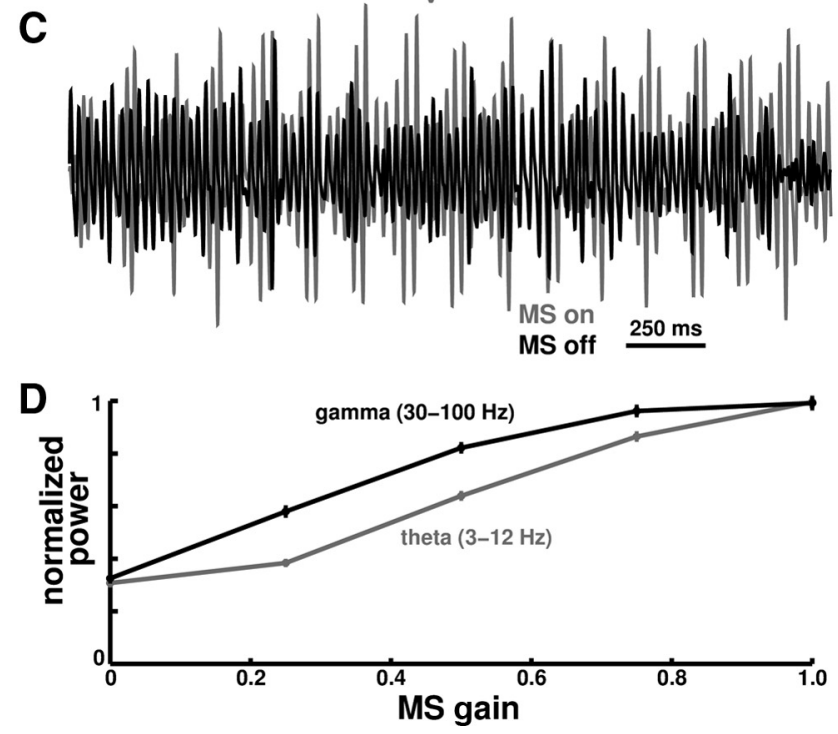

Figure 5. Medial septum input amplifies theta and gamma oscillations. $\boldsymbol{A}$, Unfiltered LFP. $\boldsymbol{B}$, LFP theta band (3-12 Hz). C, LFP gamma band ( $30-100 \mathrm{~Hz})$. D , Normalized theta and gamma power as a function of MS input strength. Error bars are SEM from 25 simulations.

also see the role of the basket cell as a contributor and amplifier of a slow rhythm simultaneous with its production of a fast one.

\section{Isolated network produces theta oscillations}

The ready entrainment of the network to MS drive suggested that the network was tuned to theta and might be capable of producing theta without a pacemaker. Leaving the rest of the network intact, we removed MS and then gradually added back this influence (Fig. 5). Absent MS, the network was able to generate intrinsic theta oscillations at $8.1 \mathrm{~Hz}$. The isolated network's theta oscillations showed greater variability in period, amplitude and frequency-band breadth than the MS-driven network. Theta activity in the isolated network was an emergent property, with frequencies not matched by any of the individual cellular or synaptic elements. Note that this frequency was not the result of specific tuning, resulting directly from the combination of standard cellular modeling time constants.

Gamma oscillation was also affected by MS input (Fig. 5C). The gradual increase in gamma oscillation amplitude paralleled the increase in the theta band (Fig. 5D). The higher gamma amplitude in the presence of MS inputs was a result of the augmentation of the theta cycle producing higher levels of both inhibition and disinhibition in cyclic alternation. As MS input strength in- 
creased, the intrinsic theta oscillations gradually shifted from the preferred firing frequency of $8.1 \mathrm{~Hz}$ down to the MSimposed rhythm of $6.7 \mathrm{~Hz}$. Gamma rhythm also showed a frequency shift, from $36 \mathrm{~Hz}$ without, to $33 \mathrm{~Hz}$ with MS input. Therefore, MS acted not only as pacemaker and phasesetter for theta but also amplified across a range of frequencies. MS inputs were present in the remainder of the simulations to provide in vivo-like conditions.

Investigating ketamine's site of action Systemic ketamine reduces theta and increases gamma in mice (Ehrlichman et al., 2009; Lazarewicz et al., 2010), rats (Sabolek et al., 2006), and humans (Hong et al., 2010). Turning off NMDA synapses in the simulation reduced activity in all cell types, resulting in significant reduction in power for both theta and gamma: -13.64 SD (SDs from mean-see Materials and Methods); -3.87 SD, respectively. These results (theta down, gamma down) did not match the experimental data (theta down, gamma up). However, different NMDA receptor subtypes, expressed on different cell types, will have different sensitivity to specific NMDA-receptor antagonists (Bresink et al., 1995; Cull-Candy et al., 2001). We hypothesized that the discrepancy might be due to ketamine producing more or less effects on the different cell types at the subanesthetic doses used.

To explore this, we performed a set of 400 simulations, turning on and off the NMDA of each synapse type in all combinations (Fig. 6). Since there were four NMDA receptor locations: OLM soma, basket soma, pyramidal basal dendrite, and pyramidal apical dendrite, this resulted in 16 binary combinations of NMDA states. Many combinations produced no large changes in gamma and theta power: 1001, 1011, 1101 ( 1 on, 0 off for NMDA receptors on the 4 locations in following order: OLM soma, basket soma, pyramidal basal dendrite, pyramidal apical dendrite). Any combination that involved turning off NMDA conductance at pyramidal cell apical dendrites $(x x x 0$, where $x$ is either 0 or 1 ), showed reductions in both theta and gamma frequency bands similar to the 0000 results. This effect was caused by reduction in drive to the main excitatory population resulting in reduced firing of all cell types and reduced spectral power across all cell types and frequencies. Note that this is comparable to the effect of reducing MS input (Fig. 5), which reduces inhibition to both inhibitory populations, thereby secondarily reducing activity in the excitatory population.

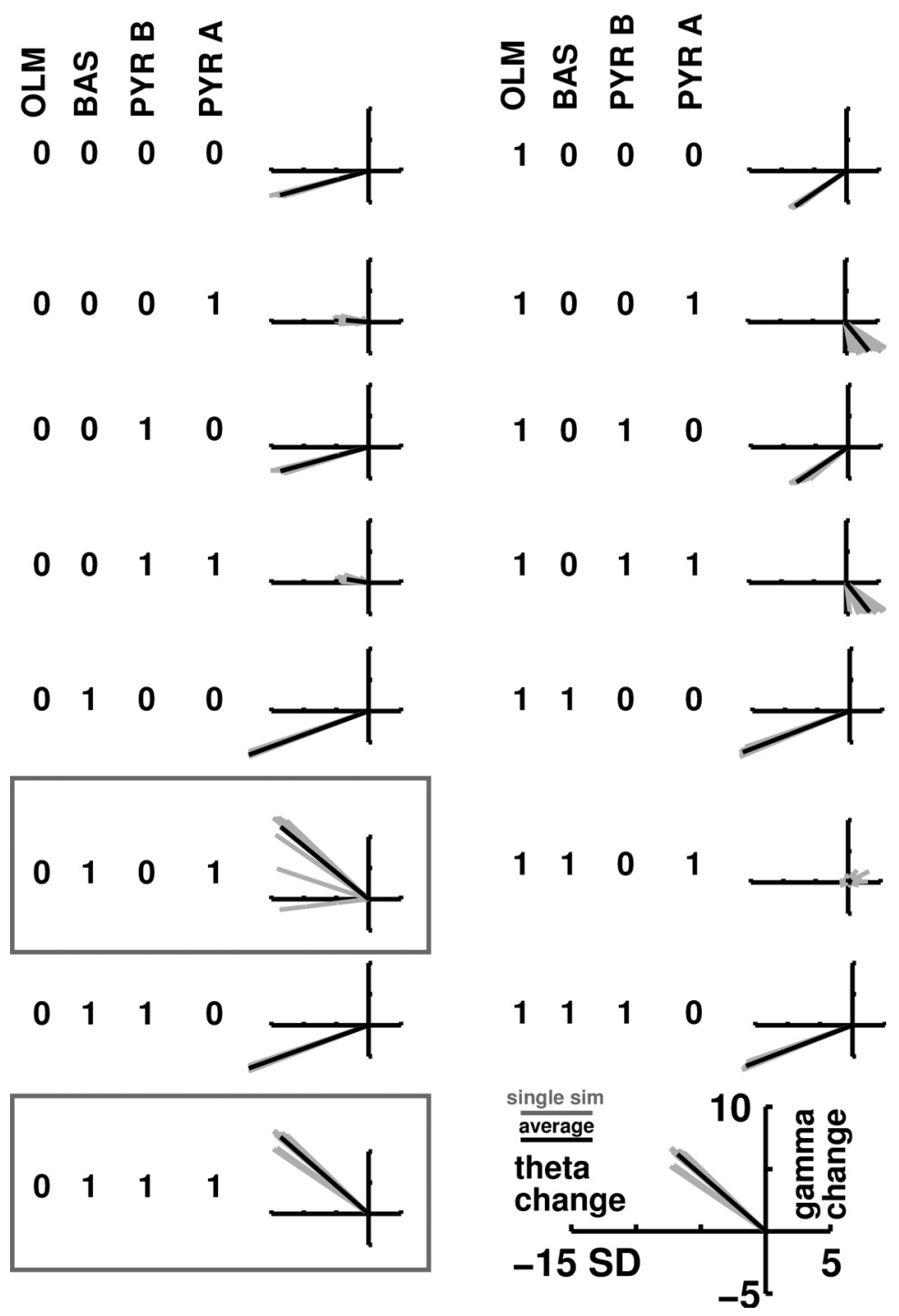

Figure 6. Changes (units of SD from mean) in gamma ( $y$-axis) and theta ( $x$-axis) with different locations of NMDA receptor blockade ( 0 represents blocked). In each plot, 25 simulations ( 5 wirings by 5 random seeds) are shown in gray with group average in black. Gray rectangle surrounds groups that matched experimental results. PYR B, Pyramidal basal dendrites; PYR A, pyramidal apical dendrites.

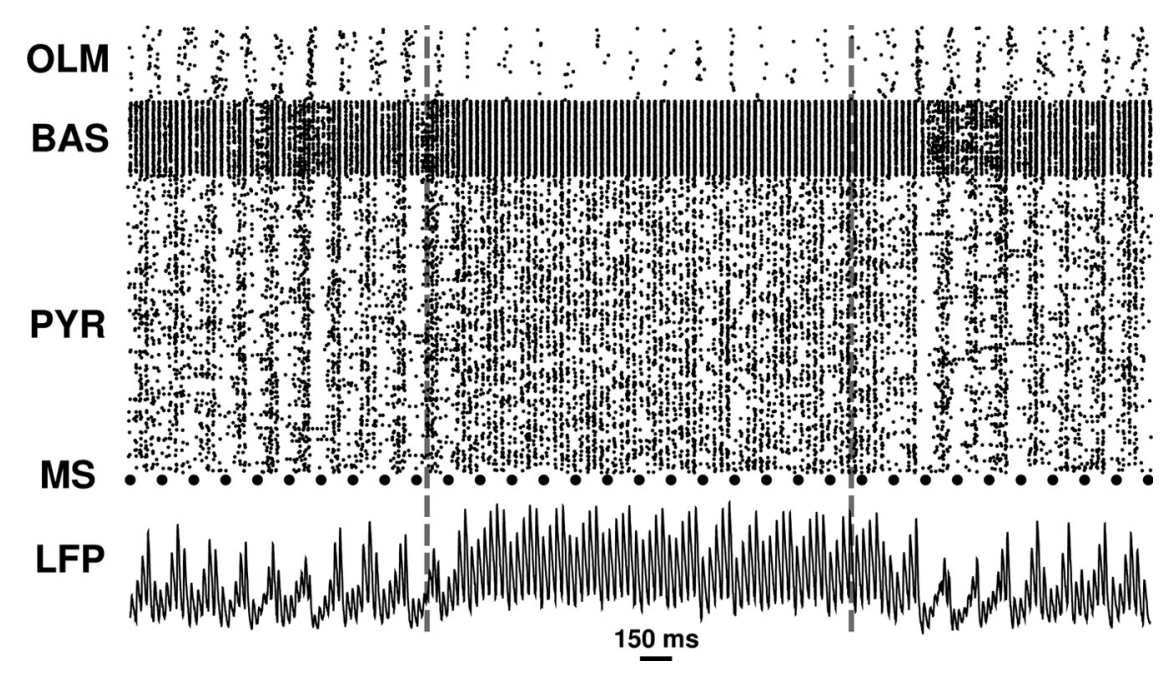

Figure 7. Ketamine effect on network firing. Raster (top) and LFP (bottom) for baseline and ketamine application between the dashed lines. 

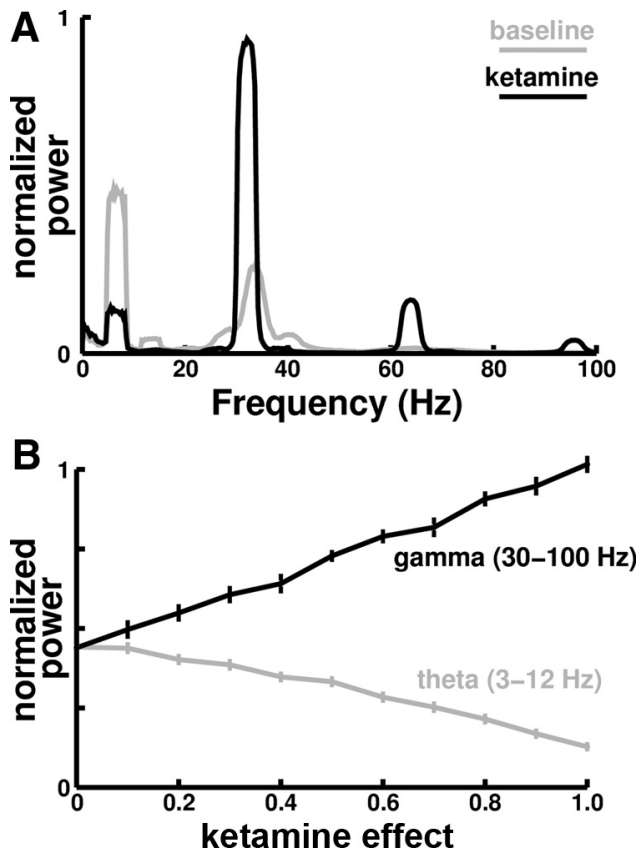

Figure 8. LFP spectral power and power changes with OLM NMDA blockade. $A$, Theta and gamma peaks change with ketamine exposure. $B$, Gamma increases and theta decreases with increased ketamine effect. Ketamine effect is $1-0$ LM NMDA conductance level. Error bars are SEM from 25 simulations.

Two combinations, 0101 (theta, gamma: $-13.57 \mathrm{SD},+11.6$ $\mathrm{SD})$ and $0111(-13.58 \mathrm{SD},+12.33 \mathrm{SD})$, replicated the experimental findings (Fig. 6, highlighted rectangles). The commonality is the blockade of NMDA receptors on OLMs. Combination 0101, with addition of pyramidal basal dendrite NMDA blockade, showed substantial gamma variability across the 25 randomizations, likely due to variably reduced pyramidal cell to basket cell drive reducing PING. We therefore predict that the experimental effect of ketamine is based on primary blockade at OLM NMDA receptors.

We evaluated the raster plots to determine the mechanism of these power shifts (Fig. 7). Simulated ketamine application weakened pyramidal cell $\rightarrow$ OLM drive, substantially reducing OLM cell firing. This then reduced the theta rhythm from OLM $\rightarrow$ pyramidal cells. A secondary effect was due to disinhibition of pyramidal cells with a shift in mean firing rate from $2.25 \mathrm{~Hz}$ to 3.35 Hz. This strengthened the dominant PING gamma, maintaining the characteristic PING frequency of $30 \mathrm{~Hz}$. Increased gamma was then due to greater pyramidal participation on each gamma cycle and tighter clustering of firing at the gamma peak. Therefore the observed increase in gamma power was not simply due to the elimination of theta, which would by itself cause an increase due to the loss of gamma dampening on the theta troughs, but represented an increase above that seen during the theta peaks in the control. Similarly, basket cells fired at almost every gamma cycle under ketamine (mean frequency of $14 \mathrm{~Hz}$ in control increasing to $25 \mathrm{~Hz}$ ). Note that increased pyramidal cell $\rightarrow$ OLM AMPA drive was not sufficient to compensate for reduced drive due to NMDA blockage.

Assessment of spectra demonstrated strong LFP theta power at $\sim 6.7 \mathrm{~Hz}$ in the control, with dispersed gamma power over $\sim 30-70 \mathrm{~Hz}$ (Fig. 8). With ketamine application, theta power was suppressed and gamma power strongly enhanced, narrowed and slightly shifted with a large peak at $\sim 30 \mathrm{~Hz}$. Two harmonics also emerged. Overall LFP power in the gamma $(30-100 \mathrm{~Hz})$ and theta $(3-12 \mathrm{~Hz})$ bands showed nearly linear negative and positive dependence with intermediate levels of OLM NMDA receptor activation (ketamine effect, Fig. $8 \mathrm{~B}$ ). In the control, power in theta and gamma bands was nearly equal. With complete OLM NMDA receptor inactivation, power in the gamma band far surpassed theta power.

\section{Restoration of normal oscillations}

The simulations suggested a sequence of pathophysiological alterations that led from a reduction in activity at a particular receptor to spectral changes at the network level. Comparable changes have been suggested to play a role in schizophrenia (Uhlhaas and Singer, 2006; Kelemen and Fenton, 2010; Lazarewicz et al., 2010). Therefore, we sought a means to restore physiological oscillations to suggest a therapeutic intervention that would restore normal dynamics. We hypothesized that a selective current injection into the OLM cell population would recover the control oscillations by direct opposition at the primary pathological focus. To test this, we replaced the lost NMDA effect, a periodic modulation from the medial septum, with a continuous current injection in all OLM cells (Fig. 9).

As expected, current injections into OLM cells raised activity levels (Fig. 9). This tonic effect was able to restore phasic activity, because the oscillation was still imposed by the GABAergic inputs from MS. With increasing current injections, overall theta power increased up to a point and then decreased. Above 20 pA, OLM cells switched to tonic firing that overcame phasic MS input and reduced both theta and gamma activity. At higher levels, tonic OLM firing reduced pyramidal activity and thereby reduced power across the spectrum.

\section{Pathological reduction in information transmission}

To move toward an understanding of the effect of this psychotomimetic drug on cognition, we assessed alteration in network information transmission as a proxy for network processing of external information. As in prior cortical studies, we hypothesized that gamma augmentation might lead to reduced information flow through the network (Neymotin et al., 2011a). Simulated application of ketamine reduced information flow from the input activation streams to network output in pyramidal cell firing as measured by normalized transfer entropy in the 125 simulations tested (nTE) (Fig. 10).

The ketamine effect (Fig. 10A) could be largely explained by the alteration it effected in gamma strength, as demonstrated by the correlation between gamma power and nTE. This reduction in information flow-through from external drive is consistent with a greater dependence on internal dynamics as a source of output variability (Neymotin et al., 2011a).

\section{Discussion}

A model of intermediate complexity (1200 neurons, multiple active ion channels, dendritic branches, two interneuron populations) was used to replicate normal and pathological hippocampal activity patterns. The model replicated several known features of normal and pathological hippocampal activity: modulation of gamma by theta; ramp-up of gamma amplitude on upslope of theta; asymmetry of theta; low cell firing rates with cycle skipping (emergent population rhythms); reduction of theta and increase of gamma with ketamine.

The simulations elucidate mechanisms for theta driving and for the coupling of theta and gamma oscillations in hippocampus. Theta driving was passed via OLMs to pyramidal cells: the OLMs inverted and propagated the MS theta and also generated 

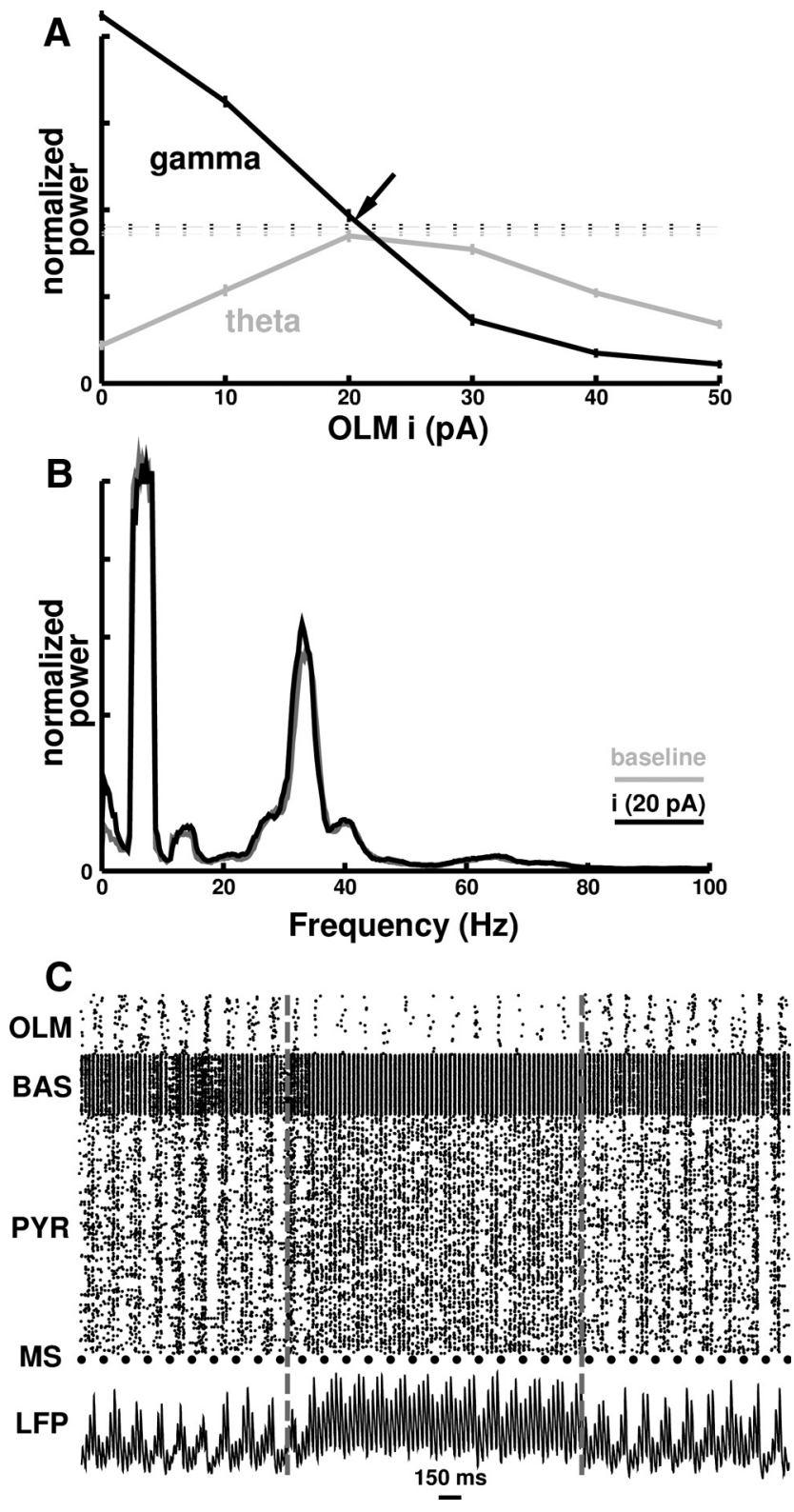

Figure 9. Restoration of phasic network activity using a tonic input. $\boldsymbol{A}$, Gamma ( $30-100 \mathrm{~Hz}$ ) and theta $(3-12 \mathrm{~Hz})$ power with ketamine and increasing amplitude of current injection into OLM. Horizontal dotted lines represent baseline power for gamma (black) and theta (gray). At $20 \mathrm{pA}$, gamma and theta power levels are restored to baseline values. $\boldsymbol{B}$, Spectral power at $20 \mathrm{pA}$ current injection compared with control shows nearly complete overlap. $\boldsymbol{C}$, Raster and LFP of activity during baseline, ketamine, and ketamine with 20 pA to OLM cells (changes at vertical lines).

theta, in the absence of MS inputs. The coupling of theta and gamma emerged as a dynamic interplay which was primarily excitatory-inhibitory (PING) but also involved some contribution by inhibitory-inhibitory (ING) effects. The convergence of these drives onto pyramidal cells provided the medium for LFP coexpression of gamma and theta. Prior simulation studies have postulated similar mechanisms to produce hippocampal oscillations through use of interactions with 2 or more populations of interneurons as primary drivers for the two dominant frequencies (White et al., 2000; Kiss et al., 2001; Orban et al., 2006; Tort et al., 2007; Cutsuridis et al., 2010).

We make a number of specific, testable, predictions from the model. The first three predictions find partial confirmation in
A

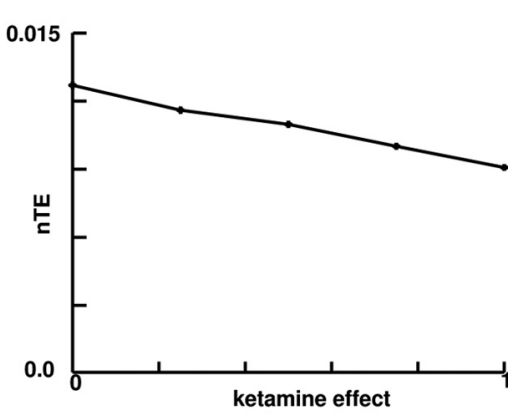

B

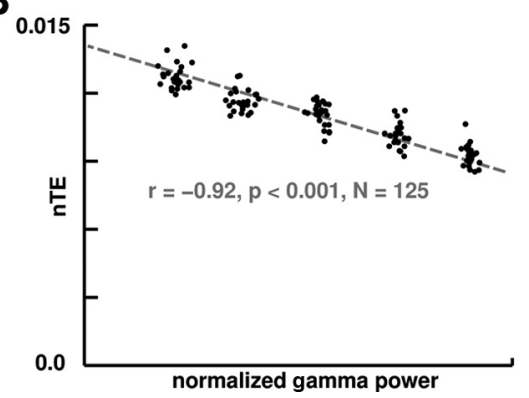

Figure 10. Reduction in information flow through network with simulated ketamine measured using nTE with $15 \mathrm{~ms}$ bin size. $\boldsymbol{A}, 30 \%$ reduction in nTE from baseline to full ketamine effect. Error bars (negligible error) are SEM from 25 simulations. Each simulation was run for $30 \mathrm{~s}$ to allow for accurate quantification of $n T E$. $B, n T E$ reduction correlates strongly with increase in gamma power. Results for all 125 simulations shown.

prior experimental work that was not used in setting up the model.

(1) OLM NMDAR antagonism will produce increased firing rates of pyramidal and basket cells. Testable by unit recording. Similar results have been obtained with related NMDAR psychotomimetics, phencyclidine and MK801 (Suzuki et al., 2002; Jackson et al., 2004).

(2) OLM NMDARs will have particular receptors with higher sensitivity to ketamine, making them a primary site of ketamine effect. This is partially supported by literature indicating that OLM cells have two novel NMDAR subtypes with distinct subunit composition (Hájos et al., 2002). There is additional prior evidence of greater density of NMDARs on OLM cells compared with basket cells (Nyíri et al., 2003).

(3) Both theta and gamma oscillations can be generated by intrinsic hippocampal circuit mechanisms in the absence of medial septal inputs. This has been shown in isolated hippocampus (Goutagny et al., 2009).

(4) Medial septal inputs will pace, augment, and band-narrow theta and gamma oscillations. Testable using optogenetics to alter firing rates of medial septal inputs.

(5) Spiking of both pyramidal and basket cells will be more tightly clustered at the gamma peak when at the theta peak. Note that this is not simply a consequence of LFP generation since LFP (produced by synaptic inputs) and spiking (outputs) are typically offset due to dendrosomatic activation delays. Pyramidal cells slightly lead basket cells at the peak of theta but tend to lag slightly at the theta trough, with some in gamma antiphase. Testable with simultaneous measurement of LFPs and single units.

(6) In addition to producing gamma, basket cells will amplify theta rhythms. Testable using optogenetics to selectively alter firing rates of basket cells (Cardin et al., 2009).

(7) The effect of ketamine on theta and gamma oscillation is based on primary blockade at OLM NMDARs. 
(8) Ketamine will produce an alteration in the relationship of firing to LFP with both basket cells and pyramidal cells firing near the peak of gamma at all phases of theta, with pyramidals slightly leading. Testable with measurement of LFPs and single units.

(9) Effects of ketamine could be reversed by providing a continuous inward current. Testable via optogenetic technology. Clinically, this predicts the possibility of reversing pathology by use of a ligand-sensitive inward-rectifying conductance fairly specific to OLM cells.

(10) Pathological augmentation of gamma will reduce responsivity to inputs. Testable as reduced alteration in MUA output with white noise multielectrode or optogenetic stimulation in vitro.

\section{Comparison of hippocampus and neocortex}

Neuronal microcircuit organization, morphologies, and chemical identity suggest conservation of design across structures, which may also be suggestive of conservation of function (Grillner et al., 2005; Silberberg et al., 2005). Both hippocampus and neocortex generate oscillations in comparable frequency bands, including theta/alpha (rat "theta" is comparable in range to primate "alpha”), beta, and gamma. Both structures also show comparable cross-frequency coupling, with theta-modulated gamma oscillations (Canolty et al., 2006).

Our recent neocortical simulation studies have demonstrated that neocortex may be tuned to generating theta/alpha oscillations intrinsically, with theta-gamma coupling emerging from feedback between excitatory and inhibitory populations (Neymotin et al., 2011b). This neocortical model used two types of interneurons but these were subdivided into 8 subsets based on layer location. Different properties of these subsets allowed them to contribute to oscillations in different frequency bands. Recent experimental evidence demonstrated that fast-spiking, somatargeting basket cells contribute to the generation of gamma oscillations (Cardin et al., 2009). However, experimental observation of interneurons in rat frontal cortex following NMDAR blockade showed reductions in rates (Homayoun and Moghaddam, 2007). This discrepancy compared with current results is likely due to a number of causes, including differences between hippocampus and cortex, the simplicity of the computer model, and the difficulty of obtaining different interneuron subtypes experimentally. It appears that distal-dendrite-targeting interneurons with slower time-constants, such as hippocampal OLM cells, contribute to slower oscillations. It has been suggested that Martinotti cells are the neocortical corollary of hippocampal OLM cells: both interneuron classes target dendrites and have relatively long time-constants (Grillner et al., 2005; Silberberg et al., 2005).

Despite commonalities, cortical mechanisms will differ in details from those in hippocampus, and will need to be independently explored in future simulations. More complete models of schizophrenia will also eventually need to incorporate neocortical-hippocampal interactions as well as additional pathological mechanisms beyond the hypothesized changes in NMDARs (Lisman et al., 2008). Strong dynamical interactions across brain areas will likely project and reinforce abnormal activity patterns arising in multiple areas.

\section{Translational multiscale modeling}

Translational multiscale modeling bridges levels to connect the molecular level where pharmacology acts, to the network and systems levels where clinical tests are performed, up to the behavioral and cognitive levels where disease is expressed (Lytton,
2008). In the present study, we have endeavored to fill in pieces of this hierarchy linking a psychotomimetic drug (molecular level), to alterations in firing (neural level), to alterations in ensemble coordination (network level), to information processing (behavioral or cognitive level). This has implications for schizophrenia, for which psychotomimetics are used to provide animal and human models (Malhotra et al., 1996, 1997; Newcomer et al., 1999; Bubeníková-Valesová et al., 2008).

We used our model to elucidate pathophysiology and investigate a possible therapeutic approach: continuous depolarizing current applied to OLM cells was capable of recovering control oscillations. We therefore predict that a possible therapeutic agent for schizophrenia would be one that activates a tonic inward current (depolarizing leak) selectively via a receptor subtype unique to OLMs. Although this therapy would target hippocampus, there might be similar changes in cortex due to related cell types with similar receptors. Additionally alterations of activity patterns in hippocampus would produce alterations in prefrontal cortex activity due to the tight dynamical links between these areas. The restoration of normal phasic activity with a tonic effector is the inverse of the situation in Parkinson's disease, where a tonic treatment (systemic levodopa) reduces or eliminates an oscillation (tremor).

Accumulating evidence suggests that gamma molds neural coordination to define representation ensembles; theta in turn molds gamma to separate and coordinate these ensembles (Gray and Singer, 1989; Canolty et al., 2006). Hippocampal gamma/ theta pathology would alter coding and learning (Fries et al., 2007; Lisman and Buzsaki, 2008), as well as altering coordination of competing information streams (Kelemen and Fenton, 2010). Based on this, an emerging pathophysiological hypothesis for schizophrenia postulates a neural coordination defect producing a cognitive coordination defect producing the cognitive core dysfunction found in schizophrenia. (Uhlhaas and Silverstein, 2005; Olypher et al., 2006; Uhlhaas and Singer, 2006).

In the heart, excessive periodicity is a sign of pathology, giving a lack of responsivity to environmental changes which normally control rate on a beat-to-beat basis (Goldberger et al., 2002). We hypothesize that schizophrenic pathophysiology would similarly reduce responsivity of a network to the environment. As in a prior study (Neymotin et al., 2011a). we found high gamma power correlated with reduction in information transmission from synaptic inputs to pyramidal spike outputs. This would then interfere with the ability of the network to reliably communicate information through hippocampus to, or from, cortex. The consequent information processing pathology would create overreliance on internal information and inadequate responsiveness to the external world, the inflexible thought and behavior patterns seen in schizophrenia (Bleuler, 1911; Parnas et al., 2002).

\section{References}

Achim AM, Bertrand MC, Sutton H, Montoya A, Czechowska Y, Malla AK Joober R, Pruessner JC, Lepage M (2007) Selective abnormal modulation of hippocampal activity during memory formation in first-episode psychosis. Arch Gen Psychiatry 64:999-1014.

Benes FM, Sorensen I, Bird ED (1991) Reduced neuronal size in posterior hippocampus of schizophrenic patients. Schizoph Bull 17:597-608.

Bleuler E (1911) Dementia Praecox oder Gruppe der Schizophrenien. In: Handbuch der Psychiatrie (Aschaffenburg G, ed). Leipzig: Deuticke.

Börgers C, Kopell N (2003) Synchronization in networks of excitatory and inhibitory neurons with sparse, random connectivity. Neural Comput 15:509-538.

Bragin A, Jandó G, Nádasdy Z, Hetke J, Wise K, Buzsáki G (1995) Gamma (40-100 hz) oscillation in the hippocampus of the behaving rat. J Neurosci 15:47-60. 
Bresink I, Danysz W, Parsons CG, Mutschler E (1995) Different binding affinities of NMDA receptor channel blockers in various brain regions-indication of NMDA receptor heterogeneity. Neuropharmacology 34:533-540.

Bubeníková-Valesová V, Horácek J, Vrajová M, Höschl C (2008) Models of schizophrenia in humans and animals based on inhibition of NMDA receptors. Neurosci Biobehav Rev 32:1014-1023.

Canolty RT, Edwards E, Dalal SS, Soltani M, Nagarajan SS, Kirsch HE, Berger MS, Barbaro NM, Knight RT (2006) High gamma power is phaselocked to theta oscillations in human neocortex. Science 313:1626-1628.

Cardin JA, Carlén M, Meletis K, Knoblich U, Zhang F, Deisseroth K, Tsai LH, Moore CI (2009) Driving fast-spiking cells induces gamma rhythm and controls sensory responses. Nature 459:663-667.

Carnevale N, Hines M (2006) The NEURON book. New York: Cambridge UP.

Cobb SR, Halasy K, Vida I, Nyiri G, Tamás G, Buhl EH, Somogyi P (1997) Synaptic effects of identified interneurons innervating both interneurons and pyramidal cells in the rat hippocampus. Neuroscience 79:629-648.

Cull-Candy S, Brickley S, Farrant M (2001) NMDA receptor subunits: diversity, development and disease. Curr Opin Neurobiol 11:327-335.

Cutsuridis V, Cobb S, Graham BP (2010) Encoding and retrieval in a model of the hippocampal CA1 microcircuit. Hippocampus 20:423-446.

Dean B, Scarr E, Bradbury R, Copolov D (1999) Decreased hippocampal (CA3) NMDA receptors in schizophrenia. Synapse 32:67-69.

Destexhe A, Rudolph M, Paré D (2003) The high-conductance state of neocortical neurons in vivo. Nat Rev Neurosci 4:739-751.

Ehrlichman RS, Gandal MJ, Maxwell CR, Lazarewicz MT, Finkel LH, Contreras D, Turetsky BI, Siegel SJ (2009) N-Methyl-D-aspartic acid receptor antagonist-induced frequency oscillations in mice recreate pattern of electrophysiological deficits in schizophrenia. Neuroscience 158:705-712.

Fries P, Nikolić D, Singer W (2007) The gamma cycle. Trends Neurosci 30:309-316.

Goldberger A, Amaral L, Hausdorff J, Ivanov P, Peng C, Stanley H (2002) Fractal dynamics in physiology: alterations with disease and aging. Proc Natl Acad Sci U S A 99S 1:2466-2472.

Gourévitch B, Eggermont JJ (2007) Evaluating information transfer between auditory cortical neurons. J Neurophysiol 97:2533-2543.

Goutagny R, Jackson J, Williams S (2009) Self-generated theta oscillations in the hippocampus. Nat Neurosci 12:1491-1493.

Gray CM, Singer W (1989) Stimulus-specific neuronal oscillations in orientation columns of cat visual cortex. Proc Natl Acad Sci USA 86:1698-1702.

Greene R (2001) Circuit analysis of NMDAR hypofunction in the hippocampus, in vitro, and psychosis of schizophrenia. Hippocampus 11:569-577.

Grillner S, Markram H, De Schutter E, Silberberg G, LeBeau FE (2005) Microcircuits in action-from CPGs to neocortex. Trends Neurosci 28:525-533.

Hájos N, Freund TF, Mody I (2002) Comparison of single NMDA receptor channels recorded on hippocampal principal cells and oriens/alveus interneurons projecting to stratum lacunosum-moleculare (O-LM cells). Acta Biol Hung 53:465-472.

Hangya B, Borhegyi Z, Szilágyi N, Freund TF, Varga V (2009) GABAergic neurons of the medial septum lead the hippocampal network during theta activity. J Neurosci 29:8094-8102.

Heckers S (2001) Neuroimaging studies of the hippocampus in schizophrenia. Hippocampus 11:520-528.

Hines ML, Carnevale NT (1997) The NEURON simulation environment. Neural Comput 9:1179-1209.

Hines ML, Carnevale NT (2001) NEURON: a tool for neuroscientists. Neuroscientist 7:123-135.

Hines ML, Davison AP, Muller E (2009) NEURON and Python. Front Neuroinform 3:1.

Holthausen EA, Wiersma D, Sitskoorn MM, Dingemans PM, Schene AH, van den Bosch RJ (2003) Long-term memory deficits in schizophrenia: primary or secondary dysfunction? Neuropsychology 17:539-547.

Homayoun H, Moghaddam B (2007) NMDA receptor hypofunction produces opposite effects on prefrontal cortex interneurons and pyramidal neurons. J Neurosci 27:11496-11500.

Honea R, Crow TJ, Passingham D, Mackay CE (2005) Regional deficits in brain volume in schizophrenia: a meta-analysis of voxel-based morphometry studies. Am J Psychiatry 162:2233-2245.

Hong LE, Summerfelt A, Buchanan RW, O’Donnell P, Thaker GK, Weiler MA, Lahti AC (2010) Gamma and delta neural oscillations and association with clinical symptoms under subanesthetic ketamine. Neuropsychopharmacology 35:632-640.

Jackson ME, Homayoun H, Moghaddam B (2004) NMDA receptor hypofunction produces concomitant firing rate potentiation and burst activity reduction in the prefrontal cortex. Proc Natl Acad Sci U S A 101:8467-8472.

Jahr CE, Stevens CF (1990) Voltage dependence of NMDA-activated macroscopic conductances predicted by single-channel kinetics. J Neurosci 10:3178-3182.

Jessen F, Scheef L, Germeshausen L, Tawo Y, Kockler M, Kuhn KU, Maier W, Schild HH, Heun R (2003) Reduced hippocampal activation during encoding and recognition of words in schizophrenia patients. Am J Psychiatry 160:1305-1312.

Kelemen E, Fenton AA (2010) Dynamic grouping of hippocampal neural activity during cognitive control of two spatial frames. PLoS Biol 8:e1000403.

Kiss T, Orbán G, Lengyel M, Erdi P (2001) Intrahippocampal gamma and theta rhythm generation in a network model of inhibitory interneurons. Neurocomputing 38:713-719.

Kolomeets NS, Orlovskaya DD, Uranova NA (2007) Decreased numerical density of CA3 hippocampal mossy fiber synapses in schizophrenia. Synapse 61:615-621.

Lazarewicz MT, Ehrlichman RS, Maxwell CR, Gandal MJ, Finkel LH, Siegel SJ (2010) Ketamine modulates theta and gamma oscillations. J Cogn Neurosci 22:1452-1464.

Lisman J, Buzsáki G (2008) A neural coding scheme formed by the combined function of gamma and theta oscillations. Schizophr Bull 34:974-980.

Lisman JE, Coyle JT, Green RW, Javitt DC, Benes FM, Heckers S, Grace AA (2008) Circuit-based framework for understanding neurotransmitter and risk gene interactions in schizophrenia. Trends Neurosci 31:234-242.

Lytton WW (2006) Neural query system: data-mining from within the NEURON simulator. Neuroinformatics 4:163-176.

Lytton WW (2008) Computer modelling of epilepsy. Nat Rev Neurosci 9:626-637.

Lytton WW, Sejnowski TJ (1991) Simulations of cortical pyramidal neurons synchronized by inhibitory interneurons. J Neurophysiol 66:1059-1079.

Malhotra AK, Pinals DA, Weingartner H, Sirocco K, Missar CD, Pickar D, Breier A (1996) NMDA receptor function and human cognition: the effects of ketamine in healthy volunteers. Neuropsychopharmacology 14:301-307.

Malhotra AK, Pinals DA, Adler CM, Elman I, Clifton A, Pickar D, Breier A (1997) Ketamine-induced exacerbation of psychotic symptoms and cognitive impairment in neuroleptic-free schizophrenics. Neuropsychopharmacology 17:141-150.

Narr KL, Thompson PM, Szeszko P, Robinson D, Jang S, Woods RP, Kim S, Hayashi KM, Asunction D, Toga AW, Bilder RM (2004) Regional specificity of hippocampal volume reductions in first-episode schizophrenia. Neuroimage 21:1563-1575.

Newcomer JW, Farber NB, Jevtovic-Todorovic V, Selke G, Melson AK, Hershey T, Craft S, Olney JW (1999) Ketamine-induced NMDA receptor hypofunction as a model of memory impairment and psychosis. Neuropsychopharmacology 20:106-118.

Neymotin SA, Jacobs KM, Fenton AA, Lytton WW (2011a) Synaptic information transfer in computer models of neocortical columns. J Comput Neurosci 30:69-84.

Neymotin SA, Lee H, Park E, Fenton AA, Lytton WW (2011b) Emergence of physiological oscillation frequencies in a computer model of neocortex. Front Comput Neurosci 5:19.

Nyíri G, Stephenson FA, Freund T, Somogyi P (2003) Large variability in synaptic $\mathrm{N}$-methyl-D-aspartate receptor density on interneurons and a comparison with pyramidal-cell spines in the rat hippocampus. Neuroscience 119:347-363.

Olypher AV, Klement D, Fenton AA (2006) Cognitive disorganization in hippocampus: a physiological model of the disorganization in psychosis. J Neurosci 26:158-168. 
Oppenheim A, Schafer R, Buck J (1999) Discrete-time signal processing, Ed 2. Upper Saddle River, NJ: Prentice Hall.

Orbán G, Kiss T, Erdi P (2006) Intrinsic and synaptic mechanisms determining the timing of neuron population activity during hippocampal theta oscillation. J Neurophysiol 96:2889-2904.

Parnas J, Bovet P, Zahavi D (2002) Schizophrenic autism: clinical phenomenology and pathogenetic implications. World Psychiatry 1:131-136.

Phillips W, Silverstein S (2003) Convergence of biological and psychological perspectives on cognitive coordination in schizophrenia. Behav Brain Sci $26: 65-82$.

Sabolek H, Penley S, Bunce J, Hinman J, Chrobak J (2006) Ketamine alters synchrony throughout the hippocampal formation. Soc Neurosci Abstr 32:751.12.

Silberberg G, Grillner S, LeBeau FE, Maex R, Markram H (2005) Synaptic pathways in neural microcircuits. Trends Neurosci 28:541-551.

Stacey WC, Lazarewicz MT, Litt B (2009) Synaptic noise and physiological coupling generate high-frequency oscillations in a hippocampal computational model. J Neurophysiol 102:2342-2357.

Stewart M, Fox SE (1990) Do septal neurons pace the hippocampal theta rhythm? Trends Neurosci 13:163-168.

Suzuki Y, Jodo E, Takeuchi S, Niwa S, Kayama Y (2002) Acute administration of phencyclidine induces tonic activation of medial prefrontal cortex neurons in freely moving rats. Neuroscience 114:769-779.

Szeszko PR, Goldberg E, Gunduz-Bruce H, Ashtari M, Robinson D, Malhotra AK, Lencz T, Bates J, Crandall DT, Kane JM, Bilder RM (2003) Smaller anterior hippocampal formation volume in antipsychotic-naive patients with first-episode schizophrenia. Am J Psychiatry 160:2190-2197.

Tamminga CA, Stan AD, Wagner AD (2010) The hippocampal formation in schizophrenia. Am J Psychiatry 167:1178-1193.
Tiesinga P, Sejnowski TJ (2009) Cortical enlightenment: are attentional gamma oscillations driven by ING or PING? Neuron 63:727-732.

Tort AB, Rotstein HG, Dugladze T, Gloveli T, Kopell NJ (2007) On the formation of gamma-coherent cell assemblies by oriens lacunosummoleculare interneurons in the hippocampus. Proc Natl Acad Sci U S A 104:13490-13495.

Uhlhaas PJ, Silverstein SM (2005) Perceptual organization in schizophrenia spectrum disorders: empirical research and theoretical implications. Psychol Bull 131:618-632.

Uhlhaas PJ, Singer W (2006) Neural synchrony in brain disorders: relevance for cognitive dysfunctions and pathophysiology. Neuron 52:155-168.

Uhlhaas PJ, Phillips WA, Mitchell G, Silverstein SM (2006a) Perceptual grouping in disorganized schizophrenia. Psychiatry Res 145:105-117.

Uhlhaas PJ, Phillips WA, Schenkel LS, Silverstein SM (2006b) Theory of mind and perceptual context-processing in schizophrenia. Cogn Neuropsychiatry 11:416-436.

Wang XJ (2002) Pacemaker neurons for the theta rhythm and their synchronization in the septohippocampal reciprocal loop. J Neurophysiol 87:889-900.

Wang XJ, Buzsáki G (1996) Gamma oscillation by synaptic inhibition in a hippocampal interneuronal network model. J Neurosci 16:6402-6413.

White JA, Banks MI, Pearce RA, Kopell NJ (2000) Networks of interneurons with fast and slow GABA type A (GABAA) kinetics provide substrate for mixed gamma-theta rhythm. Proc Natl Acad Sci U S A 97:8128-8133.

Whittington MA, Traub RD, Kopell N, Ermentrout B, Buhl EH (2000) Inhibition-based rhythms: experimental and mathematical observations on network dynamics. Int J Psychophysiol 38:315-336.

Zaidel DW, Esiri MM, Harrison PJ (1997) Size, shape, and orientation of neurons in the left and right hippocampus: investigation of normal asymmetries and alterations in schizophrenia. Am J Psychiatry 154:812-818. 